\title{
Effect of health belief model (HBM) - based education on the prevention of Osteoporosis in female administrative staffs of Guilan University of Medical Sciences, Rasht, Iran
}

\author{
Research Article
}

\section{Zeynab Abolhasani ${ }^{1}$, Nasrin Mokhtari Lakeh ${ }^{2 *}$}

1. MSc of Nursing, Nursing faculty, Guilan University of Medical Sciences, Rasht, Iran. 2. Nursing faculty, Guilan University of Medical Sciences, Rasht, Iran.

\begin{abstract}
Aims and Objectives: Osteoporosis is one of the most important metabolic bone disease and health problems worldwide. The study's objective is to investigate the effect of health belief model based education on the prevention of osteoporosis in female administrative staffs in Iran. Methods: In this quasi-experimental study, 110 female administrative staffs in medical, dentistry, pharmacy, health, nursing and midwifery faculties of Guilan University of Medical Sciences in Rasht, Iran, were selected in 2016-2017. The data collection was carried out using: 1-Demographic information 2- Osteoporosis knowledge questionnaire, 3- Osteoporosis health beliefs questionnaire. Both experimental and control groups were evaluated in three stages. Results: The results of the present study showed that the majority of the studied subjects were married (84.5\%), aged 35-40 (44.5\%), had undergraduate degrees $(62.7 \%)$, and their field of study was humanities $(80.9 \%)$. Independent $t$-test showed that the pre-intervention mean score of all dimensions of Perceived Knowledge, Perceived Susceptibility, Perceived Seriousness, Perceived Benefits, Calcium's Perceived Benefits, Osteoporosis prevention Perceived Barriers, Physical Perceived Barriers was not statistically significant in both groups $(\mathrm{p}>0.05)$, but such score was statistically significant in both experimental and control groups one day and one month after $(\mathrm{P}<0.0001)$. Conclusions: Findings of the research indicate that the health belief model can help to raise knowledge, perceived susceptibility, and perceived severity of the consequences and risks of a disease with an unhealthy behavior, as well as achieve an understanding of the benefits and barriers to a healthy behavior.
\end{abstract}

Keywords: Health belief model, prevention, osteoporosis, administrative staffs.

\section{Introduction}

Osteoporosis is one of the most important health problems worldwide. Osteoporosis has been known for a long time, but it has not been paid much attention, because it showed no clinical symptoms until its complications occur, and on the other hand, there was no diagnostic tool (2). World Health Organization (WHO) declared in 1991 osteoporosis as the fourth main human enemy after myocardial infarction, stroke, and cancer and the most common cause of bone fracture worldwide $(2,4)$. According to the National Osteoporosis Foundation, the disease threatens 44 million Americans, with 10 million individuals are infected and 34 million individuals have low bone mass $(6,7,8)$. The annual cost of osteoporosis-induced fractures in the United States is estimated at 12-17 billion dollars, and if effective and preventative activities are not continuously promoted, the global cost of osteoporosis is predicted to rise to more than 60 billion dollars by 2020 (9). According to the

\footnotetext{
*Corresponding Author:

Nasrin Mokhtari Lakeh

Nursing faculty,

Guilan University of Medical Sciences,

Rasht, Iran.

Email id:1akeh@gums.ac.ir
}

Endocrinology and Metabolism Research Institute affiliated to Tehran University of Medical Sciences, 6 million Iranians are suffering from osteoporosis and out of every 5 million postmenopausal women, 2.5 million are suffering from osteoporosis. Osteoporosis is also common or reduced bone mass among $50 \%$ of men and $70 \%$ of women over 50 years of age $(4,10)$. In addition, there are 200-400 thousand cases of fractures occur every year, with osteoporosis accounting for a high proportion of them. The annual expenditures imposed on the government due to the pelvic fracture and subsequent surgeries are estimated at 120 billion rials (11). Women are eight times more likely to have the disease than men. More than half of the women over the age of 50 are affected by the disease, with around 200 million women suffering from the disease worldwide (5). Considering significant economic and social costs, osteoporosis is an important health issue that must be taken into account by healthcare providers and prevention strategies should be considered as a priority in the health care $(11,12)$. Gender, menopause, race, skeletal size, caffeine consumption, estrogen reduction, early menopause, decreased calcium intake and physical inactivity are considered as risk factors for this disease (4). It should be noted that although health and wellbeing are a matter to be considered among all the social strata and age groups, due to the higher incidence of 
osteoporosis among women in all age groups as compared to than men, and since women are key members of the society and make up half of the world's population, it is necessary to have enough knowledge and information in this regard and maintaining their health and hygiene status is thus vital (11). Education is one of the ways to reduce the prevalence of osteoporosis. In general, every case that requires the transformation of human behavior in the field of health, the topic of health education is raised as a learning process that empowers people to voluntarily change the conditions by modifying their behavior to enhance their health status (13). In this regard, in order to have an appropriate understanding of inappropriate health behaviors of people and to prevent institutionalization of inappropriate life styles, as well as to increase the effectiveness of education, educational programs should be based on existing educational theories (14). One of these theories is the health belief model (HBM), which is one of the most widely used models concerning health behaviors. It is considered as an individual health behavior study model that measures the relationship between health belief and health behavior and is based on the hypothesis that preventive behavior depends on the individual's belief (4). This model is one of the first theories developed solely for the health-related behaviors and initially developed as a structural practice for expressing and anticipating preventive health-related behaviors. This model consists of five components that include knowledge, perceived susceptibility, perceived severity, perceived benefits, perceived barriers, and self -efficacy. HBM assumes that health-related behavior depends on the simultaneous occurrence of three categories of factors: 1. Existence of sufficient motivation to highlight health issues. 2 . The belief that a person is susceptible to a serious health problem or its consequences such as morbidity or disorder, which is often called a perceived threat. 3. The belief that pursuing a specific health recommendation would be mentally helpful in reducing perceived threats at a reasonable expense. This model has been used in behavioral research, primary prevention and secondary prevention (13). Some researches where HBM has been used are as follows: Creating a health belief scale for AIDS, promoting the use of helmet, breast cancer screening tool, promoting healthy nutritional behavior, determining predictors of healthy behavior in students, smoking in students, socio-psychological modeling for diabetic patients, promoting anti-hepatitis vaccination, screening for cervical cancer, osteoporosis, and tuberculosis (14). The main components of this model include perceived threats (which are themselves influenced by both perceived susceptibility and perceived severity), perceived barriers, perceived benefits, cues to action, and self-efficacy. Based on this model, to take preventive measures for osteoporosis, individuals should first feel the risk to the problem (osteoporosis risk factors) (perceived susceptibility), and then perceive the depth of this risk and the seriousness of its various complications in terms of physical, social, psychological, and economic dimensions (perceived severity), believe the usefulness and feasibility of osteoporosis prevention program (perceived benefits), and have confident in their ability to overcome the osteoporosis barriers (perceived barriers) to eventually, take preventive measures. HBMbased education can be effective in promoting osteoporosis-preventative behaviors $(2,4,15,16)$. There have been many studies on the effect of education, especially HBM-based education on osteoporosis. In this regard, in a study entitled "The effect of HBMbased education on the prevention of osteoporosis in postmenopausal women," Torshizi (2009) showed that education had an effect on increased perceived susceptibility and severity and reduced barriers to exercise (57). In a study on HBM-based education on the social factors associated with the osteoporosispreventive behavior in women based, Bagherian Moghaddam (2016) showed a direct and positive correlation between the level of knowledge, perceived benefits, cues to action, and self-efficacy with women's performance on the osteoporosis-preventive behavior and perceived barriers was inversely correlated with women's performance (58). In another study on effect of HBM-based education on modifying women's lifestyle and adopting osteoporosis-preventive behaviors, Vahedian-Shahroodi (2016) showed a significant difference between the two groups in terms of their level of knowledge , perceived severity, self-efficacy, practice guide, perceived benefits, and post- intervention calcium intake and control of confounding variables (59). In another study, Khorsandi (2013) measured the correlation between HBM components and osteoporosis -preventive behaviors in pregnant women in Arak. The results showed a positive correlation between perceived susceptibility, severity, benefits, and self-efficacy with the performance of pregnant mothers on the prevention of osteoporosis, and there was a negative correlation between perceived barriers and performance. Also, the lower the knowledge, perceived severity, self-efficacy and the perceived barriers in carrying out osteoporosispreventive behaviors in pregnant mothers led to higher performance in them (60). From the health perspective, one of the most important problems in today's society is the reduction of physical activity among individuals (17). One of the main goals of WHO is to increase the number of osteoporosis-trained women $(5,9,10)$. This group of people is less concerned about their health status because of their life responsibilities. Changes in lifestyle, especially the sufficient calcium and vitamin D intake and exercise, are among the most commonly recommended measures to prevent osteoporosis, and despite these preventive recommendations, most people, especially women, do not apply these recommendations. Therefore, according to the above studies in Iran, the high prevalence of osteoporosis and related problems 
have still been reported. Also, given the long-term use of computers by the university's staffs, it can be said that this group of people, as one of the occupational groups, is at risk of developing bone diseases due to their low mobility (18). Moreover, considering the high rate of immobility among working women, it is vital to investigate this group of people and provide educational services to them. Therefore, considering such importance, high prevalence of osteoporosis in women, and the lack of a similar study on the administrative staffs of Guilan University of Medical Sciences, the aim of this study was to determine the effect of HBM-based education on the prevention of osteoporosis in female staffs in Guilan University of Medical Sciences.

\section{Materials and Methods}

This is a quasi-experimental research carried out in 2016-2017. The research setting was Guilan University of Medical Sciences and Rasht city. The research population included all female administrative staffs. The research samples consisted of 110 female administrative staffs in medical, dentistry, pharmacy, health, nursing and midwifery faculties of Guilan University of Medical Sciences in Rasht city. They were selected as the subjects if they had inclusion criteria (employment in administrative departments of faculties affiliated to Guilan University Medical Sciences), being female, and having no osteoporosis disease). The census sampling method was used. To do so, a list of all female administrative staffs in the research population including 201 was first prepared. Then, in order to homogenize the samples in terms of their level of knowledge about osteoporosis, the osteoporosis knowledge questionnaire was given to all 201 staffs from the total number of faculties, and 127 staffs were then placed in the poor knowledge group after receiving information about their level of knowledge about osteoporosis, using a standard questionnaire, underwent psychometric analysis, developed by Bahiraei et al. (56). Finally, 110 staffs met the research criteria and the sample size per group was calculated as 55 individuals according to the sample size formula and Shojaei Zadeh et al. (4). Then, they were divided into experimental and control groups based on random allocation. To do so, the first individual was assigned to the control group and the second individual to the experimental group one in between and this process continues. The data collection was carried out using: 1-Demographic information 2- Osteoporosis knowledge questionnaire, 3 - Osteoporosis health beliefs questionnaire. The first part of the questionnaire included demographic questions, which included 5 questions (age, level of education, marital status, field of study, and history of disease), the second part of the questionnaire included osteoporosis knowledge and health belief questionnaire, which consisted of 24 questions with each question having a correct answer (56). Scores 1 and 0 were assigned to the correct and wrong answers, respectively.
The possible score range was $0-24$. The individuals' level of knowledge was classified as follows: poor: 018, good and optimal: 19-24 (56). The third part consisted of a 36-item researcher-made questionnaire to assess the health belief. This questionnaire consisted of 36 questions on perceived susceptibility, severity and benefit, and barriers domains: perceived susceptibility (Questions 1-6 of the belief questionnaire), perceived severity (Questions 7-12 of the belief questionnaire), perceived benefits of osteoporosis-preventive behaviors (13-24 questions of the belief questionnaire), and perceived barriers to osteoporosis-preventive behaviors (Questions 25-36 of the belief questionnaire). Questions on the perceived susceptibility, severity, benefits, and barriers were designed using a 5-point Likert scale (Totally agree (Score 5), Agree (Score 4), I have no idea (Score 3), Disagree (Score 2), Totally disagree (Score 1), with the highest and lowest scores of 5 and 1 , respectively. The content and face validity of the questionnaire was confirmed using the panel of experts. Also, the internal consistency of the constructs was obtained by obtaining the Cronbach's alpha coefficient in the acceptable range of 86.0. Both experimental and control groups were evaluated in three stages. First stage: before intervention, second stage: immediately one day after intervention, third stage: one month after intervention. To train the subjects in the experimental group, the HBM-based educational content, defined as osteoporosis, symptoms of the disease, and risk factors, diagnosis and treatment, and the prevention measures, including calcium intake and exercise in the form of an osteoporosis manual and educational pamphlets were given to each individual in this group. The content of the educational guide was prepared according to the research objectives and tailored to the educational needs of the people (based on the pre-test). The validity of the questionnaire was also confirmed based on the opinions of ten faculty members. Immediately one day later, both groups were evaluated, and both groups were reevaluated to assess the retention of the training one month after the training. Data analysis was carried out using SPSS ver. 22. To evaluate the effect of education on staffs' health knowledge and beliefs, the paired t-test was used for each domain in the measurement periods. Non-parametric Mann-Whitney $U$ and Wilcoxon tests were also used to compare the changes in health knowledge and beliefs in intervention and nonintervention groups. To evaluate the process of knowledge and belief change in the two groups, repeated measures ANOVA was used. P-value $<0.05$ was considered as the significance level in all tests in this study. In order to collect data after confirmation of the research title in the health deputy, the approval of the Ethics Committee (No. 2930003616) was obtained. Then the researcher selected the subjects as the samples after receiving a written introduction letter from the Faculty of Nursing and Midwifery of Shahid Beheshti of Rasht and the Vice Chancellor for Research of 
Guilan University of Medical Sciences and presenting it to the authorities of faculties. The researcher also invited the individuals to participate in the study after providing explanations about the research objectives and method and assuring them about the confidentiality of their information. The intervention group also explained the educational packages and how to study it. The research subjects signed a written letter of consent for participation in the research, and completed the questionnaire after being informed knowledge of the research objectives and in the case of willingness to participate in the research.

\section{Results}

The results of the present study showed that the majority of the studied subjects were married (84.5\%), aged $35-40(44.5 \%)$, had undergraduate degrees $(62.7 \%)$, and their field of study was humanities $(80.9 \%)$ (Table 1).

Table 1: Demographic Characteristics

\begin{tabular}{|c|c|c|c|}
\hline \multicolumn{2}{|c|}{ Variable } & Percent & Frequency \\
\hline \multirow{2}{*}{ Marriage } & Married & 84.5 & 93 \\
\hline & Single & 15.5 & 17 \\
\hline \multicolumn{2}{|c|}{ Total } & 100 & 110 \\
\hline \multirow{4}{*}{ Education } & Under Dip & 10 & 11 \\
\hline & Diploma & 18.2 & 20 \\
\hline & Graduate & 62.7 & 69 \\
\hline & $\begin{array}{c}\text { Upper } \\
\text { Graduate }\end{array}$ & 9.1 & 10 \\
\hline \multicolumn{2}{|c|}{ Total } & 100 & 110 \\
\hline \multirow{5}{*}{ Age } & $<30$ & 3.6 & 4 \\
\hline & $30-35$ & 24.5 & 27 \\
\hline & $35-45$ & 44.5 & 49 \\
\hline & $40-45$ & 17.3 & 19 \\
\hline & $>45$ & 10 & 11 \\
\hline \multirow{4}{*}{ Major } & & 100 & 110 \\
\hline & Humanities & 80.9 & 89 \\
\hline & Science & 11.8 & $\overline{13}$ \\
\hline & Engineering & 7.3 & 8 \\
\hline \multicolumn{2}{|c|}{ Total } & 100 & 110 \\
\hline
\end{tabular}

Independent $t$-test showed that the preintervention mean Perceived Knowledge score was not statistically significant in both groups $(\mathrm{p}=0.627)$, but such score was statistically significant in both experimental and control groups one day and one month after intervention as well as changes in such score from pre-intervention phase to one day, and from one day to one month after the intervention as well as from the preintervention phase to one month after the intervention ( $\mathrm{P}$ $<0.0001$ ). Independent t-test also showed that the preintervention mean perceived susceptibility score was not statistically significant in both groups $(\mathrm{p}=0.817)$, but such score was statistically significant in both experimental and control groups one day and one month after intervention as well as changes in such score from pre-intervention phase to one day, and from one day to one month after the intervention as well as from the pre- intervention phase to one month after the intervention ( $\mathrm{P}$ $<0.0001)$.Also, Independent t-test showed that the preintervention mean perceived Seriousness score was not statistically significant in both groups $(p=0.550)$, but such score was statistically significant in both experimental and control groups one day and one month after intervention as well as changes in such score from pre-intervention phase to one day, and from one day to one month after the intervention as well as from the preintervention phase to one month after the intervention ( $\mathrm{P}$ $<0.0001)$. Independent t-test showed that also the preintervention mean perceived severity score was not statistically significant in both groups $(p=0.505)$, but such score was statistically significant in both experimental and control groups one day and one month after intervention as well as changes in such score from pre-intervention phase to one day, and from one day to one month after the intervention as well as from the preintervention phase to one month after the intervention $(\mathrm{P}$ $<0.0001)$. Independent $t$-test showed that the preintervention mean perceived benefits score was not statistically significant in both groups $(p=0.595)$, but such score was statistically significant in both experimental and control groups one day and one month after intervention as well as changes in such score from pre-intervention phase to one day, and from one day to one month after the intervention as well as from the preintervention phase to one month after the intervention $(\mathrm{P}$ $<0.0001$ ). Also, Independent t-test showed that the preintervention mean perceived benefits of calcium intake score was not statistically significant in both groups $(\mathrm{p}=0.999)$, but such score was statistically significant in both experimental and control groups one day and one month after intervention as well as changes in such score from pre-intervention phase to one day, and from one day to one month after the intervention as well as from the pre-intervention phase to one month after the intervention ( $\mathrm{P}<0.0001)$. Also, Independent $t$-test showed that the pre-intervention mean score of perceived barriers to osteoporosis-preventive behaviors of calcium intake was not statistically significant in both groups $(p=0.32)$, but such score was statistically significant in both experimental and control groups one day and one month after intervention as well as changes in such score from pre-intervention phase to one day, and from one day to one month after the intervention as well as from the pre-intervention phase to one month after the intervention $(\mathrm{P}<0.0001)$. Also, Independent $\mathrm{t}-$ test showed that the pre-intervention mean score of perceived barriers to physical activity was not statistically significant in both groups $(p=0.19)$, but such score was statistically significant in both experimental and control groups one day and one month after intervention as well as changes in such score from preintervention phase to one day, and from one day to one month after the intervention as well as from the preintervention phase to one month after the intervention ( $\mathrm{P}$ $<0.0001$ ) (Table 2). 
Nasrin Mokhtari Lakeh et.al., Effect of HBM on prevention of osteoporosis in female staff

Table 2: Comparing Groups according to Mean Scores of Knowledge

\begin{tabular}{|c|c|c|c|c|}
\hline Outcomes & $\begin{array}{l}\text { Time } \\
\text { Group }\end{array}$ & Before & $\begin{array}{l}1 \text { day } \\
\text { after }\end{array}$ & $\begin{array}{c}1 \\
\text { month } \\
\text { after }\end{array}$ \\
\hline \multirow{3}{*}{$\begin{array}{l}\text { Perceived } \\
\text { Knowledge }\end{array}$} & Control & 15.13 & 16.80 & 15.78 \\
\hline & $\begin{array}{l}\text { Interve } \\
\text { ntion }\end{array}$ & 14.89 & 23.16 & 18.93 \\
\hline & $\mathrm{P}$ value & .627 & 0.0001 & 0.0001 \\
\hline \multirow{3}{*}{$\begin{array}{l}\text { Perceived } \\
\text { Susceptibility }\end{array}$} & Control & 11.98 & 11.20 & 10.72 \\
\hline & $\begin{array}{l}\text { Interve } \\
\text { ntion }\end{array}$ & 12.05 & 12.65 & 19.20 \\
\hline & $\mathrm{P}$ value & 0.81 & .0001 & 0.0001 \\
\hline \multirow{3}{*}{$\begin{array}{l}\text { Perceived } \\
\text { Seriousness }\end{array}$} & Control & 10.98 & 10.45 & 10.89 \\
\hline & $\begin{array}{l}\text { Interve } \\
\text { ntion }\end{array}$ & 11.21 & 27.92 & 19.09 \\
\hline & $\mathrm{P}$ value & 0.505 & 0.0001 & 0.0001 \\
\hline \multirow{3}{*}{$\begin{array}{l}\text { Perceived } \\
\text { Benefits }\end{array}$} & Control & 10.94 & 10.69 & 10.83 \\
\hline & $\begin{array}{l}\text { Interve } \\
\text { ntion }\end{array}$ & 11.12 & 27.92 & 19.16 \\
\hline & $\mathrm{P}$ value & .5950 & 0.0001 & .0001 \\
\hline \multirow{3}{*}{$\begin{array}{l}\text { Calcium's } \\
\text { Perceived } \\
\text { Benefits }\end{array}$} & Control & 10.98 & 12.05 & 11.05 \\
\hline & $\begin{array}{l}\text { Interve } \\
\text { ntion }\end{array}$ & 10.98 & 28.01 & 18.85 \\
\hline & $\mathrm{P}$ value & .9990 & 0.0001 & .0001 \\
\hline \multirow{3}{*}{$\begin{array}{l}\text { Osteoporosis } \\
\text { prevention } \\
\text { Perceived } \\
\text { Barriers }\end{array}$} & Control & 10.49 & 10.58 & 11.43 \\
\hline & $\begin{array}{l}\text { Interve } \\
\text { ntion }\end{array}$ & 10.76 & 27.83 & 18.90 \\
\hline & $\mathrm{P}$ value & .3230 & 0.0001 & 0.0001 \\
\hline \multirow{3}{*}{$\begin{array}{l}\text { Physical } \\
\text { Perceived } \\
\text { Barriers }\end{array}$} & Control & 10.69 & 11.18 & 28.03 \\
\hline & $\begin{array}{l}\text { Interve } \\
\text { ntion }\end{array}$ & 11.16 & 11.63 & 19.03 \\
\hline & $\mathrm{P}$ value & 0.1970 & 0.0001 & 0.0001 \\
\hline
\end{tabular}

\section{Discussion}

The results of the study indicate no significant difference between both intervention and nonintervention groups in terms of the mean knowledge score in the first stage (before the intervention), but in the second stage (immediately after the intervention), and the third stage (one month after the intervention, the mean knowledge score changed in both groups. The researcher believes that the reason for lower knowledge score is that retention of information and material learnt can be reduced over time, if learning is not continuous. It can also be said that HBM-based education of a health behavior increases knowledge and the findings of this study are consistent with similar studies. In a study on 206 female students, Hazavehei et al. (2007) collected information in three stages; namely before, immediately, and one month after the intervention using a questionnaire and showed that the individuals' level of knowledge increased significantly after the intervention (15). The findings of this study are similar to those of Ghaffari et al.'s study (2009-2010). In their study titled" The effect of HBM-based on promoting osteoporosispreventive behaviors in female second-grade middle school students in Isfahan, Ghaffari et al. concluded that the knowledge of female students in the experimental group has significantly increased after the intervention
(16). Also, the results of this study showed that HBMbased education has led to a significant increase in the perceived susceptibility of the risks and consequences of osteoporosis in the experimental group after the intervention. These findings were consistent with the results of the similar study carried out by Shojaeezadeh et al. In a study "entitled "The effect of HBM-based education in the prevention of osteoporosis in healthcare providers of Khorramabad HealthCare Centers in 2011", Shojaei Zadeh et al., carried out an intervention on 100 healthcare providers divided into 2 groups $(n=50$ individuals per group). The results showed that perceived susceptibility to osteoporosis was increased significantly in the experimental group after the intervention (4). Consistent with the present study, in a study entitled "The effect of HB M-based education on the use of osteoporosis-preventive measures in postmenopausal women", Torshizi et al. (2009), conducted an intervention in experimental and control groups. The experimental group participated in a predesigned educational program and independent-t test showed significant differences between the two groups in terms of perceived susceptibility after the intervention (51). However, in a study entitled "The effect of HBMbased education on osteoporosis prevention among Taiwanese women, Huang et al., (2011) stated that such education did not affect the perceived susceptibility of individuals regarding the osteoporosis (53). In a study entitled "The effect of HBM-based intervention on the prevention of osteoporosis in female students of Shaker University in Saudi Arabia in 2013, Al Serati found that perceived susceptibility increased in the intervention group after the education, which were consistent with the results of the present study (55). The results of the present study also showed that the perceived severity of the risks and consequences of osteoporosis increased significantly in the intervention group, after the intervention, which are consistent with the study of Tuassing et al. (2005), entitled "Osteoporosis prevention education: behavioral theories and calcium intake" based on health belief model and expectancy-value theory. The study also showed that the perceived severity of osteoporosis was increased in the intervention group after intervention (37). Hazavehei et al. (2007) also showed that HBM has increased the perceived severity of individuals in adopting osteoporosis-preventive approaches (15). In their study entitled "The Effect of HBM-based education on promoting osteoporosis-preventive behaviors of in female second-grade middle school students in Isfahan", Ghaffari et al., (2011) showed that the perceived severity of osteoporosis of the experimental group, was significantly increased after intervention (16). The results of this study are also consistent with the findings of Ebadi Fard Azar et al.'s research (2009) entitled "The effect of HBM on osteoporosis-preventive behaviors of in Malayer Women" (11). However, in a study entitled "The effect of HBM education on osteoporosis 
prevention program among Taiwanese women", Huang et al.(2011) showed such education had no effect on perceived severity of osteoporosis (53). Also, comparing the perceived benefits of osteoporosis-preventive behaviors (physical activity and calcium intake) at different stages in both intervention and nonintervention groups indicated that the perceived benefits of physical activity and calcium intake in the trained group significantly increased. Similarly, in a study entitled "Osteoporosis prevention education, behavioral theories and calcium intake among on 42 women during an eight- week intervention based on the health belief model and expectancy value theory, Tuassing et al. (2005) found that the perceived benefits of the calcium intake have increased in the experimental group after the intervention (37). In their study entitled "The Effect of HBM-based education on osteoporotic-preventive behaviors in Healthcare provider in Khoram Abad, Shojaeezadeh et al.(2010) stated that the perceived benefits score for physical activity and calcium intake has significantly increased in the experimental group after the intervention $(\mathrm{P}<0.0001)$. Also, the results of Torshizi et al. (51), Al serati et al (55), and Ghaffari et al. (16) are consistent with the findings of the present study. Also, the results of comparing the perceived barriers to osteoporosis-preventive behaviors (physical activity and calcium intake) in different stages of intervention in both intervention and non-intervention groups showed that a significant difference between both groups in terms of mean perceived barriers score. Te results of this study are also consistent with Hazavehei et al.'s study (2007), entitled "Use of health belief model for the osteoporosis prevention among female middle school students in Garmsar (15). Tuassing (2005) also found similar findings that perceived barriers to physical activity education increased significantly in the experimental group after the intervention (37). In a study entitled "The effect of HBM-based educational intervention in osteoporosis prevention in healthcare providers of Khoram Abad healthcare centers", Shojaeizadeh et al. (2010) found that the score of perceived barriers to physical activity and calcium intake increased significantly in the experimental group compared with the control group after educational intervention $(\mathrm{P}<0.0001)$, which is consistent with the findings of the present study (4). Also, the results of many other studies $(8,11,16,51)$ are consistent with the results of the current study.

\section{Conclusion}

Considering the general aim of the research and data analysis, the hypotheses and results analysis, it can be concluded that that there was a significant increase in the scores of the intervention group compared to the non -intervention group in all domains and components of the health belief model after intervention. Findings of the research indicate that the health belief model can help to raise knowledge, perceived susceptibility, and perceived severity of the consequences and risks of a disease with an unhealthy behavior, as well as achieve an understanding of the benefits and barriers to a healthy behavior. However, in addition to training and educational interventions to raise individuals' level of knowledge of osteoporosis, attempts should be made to investigate the resisting against preventive behaviors of osteoporosis since simply by giving education and positive motivation, one cannot persuade a person to conduct a healthy behavior so as to achieve desired results and create the healthy behaviors at the individual and social levels. The training has a profound effect on promoting the learning of osteoporosis-preventive methods at younger age groups. It is difficult to change beliefs that are derived from people's belief systems or have been institutionalized for a long time and the use of models and behavior change theories in health education are effective in achieving such goal.

\section{References}

1. Stanhope M, Lancaster J, Community and Public Health Nursing. 6th Edition, St. Luis; Mosby Inc; 2004. $111 \mathrm{p}$.

2. Vahedian-Shahroodi M, Elaheh L.M, Esmaily H, Tehrani H, Hamidreza M.H, Prediction of osteoporosis preventive behaviors using the Health Belief Model. Iranian Journal of Health Education and Health Promotion. 2014 Dec 15; 2(3):199-207.

3. Tehrani H, khanjanin,Majlesi F, Modern mediabased intervention on promotion of womensactivity.wulfenia journal.2014;21(6):70260.

4. 4-Shohaezadeh D, sadeghi R, Tarrahi M, Asadi M, Laskgarara B, Application of health Belief Model in Prevention of osteoporosis in Volunteers of khorramabad city health centers, Iran. Health System Research. 2012; 8(2): 183-192.

5. Khani Jeihooni A, Hidarnia A, Kaveh M.H, Hajizadeh E, Gholami T, Survey of osteoporosis preventive behaviors among women in Fasa: The Application of the Health Belief Model and Social Cognitive Theory. Iran South Med J. 2016; 19(1):48 -62 .

6. Ahmadnia E, Shakibazadeh E, Emamgholi Khooshehcheen T, Life Style-Related Osteoporosis Preventive Behaviors among Nursing and Midwifery Students. Hayat. 2010; 15 (4) :50-59

7. Edmonds E, Turner L.W, Usdan S.L, Osteoporosis knowledge, beliefs, and calcium intake of college students: Utilization of the health belief model. Open Journal of Preventive Medicine. 2012 Feb 23;2(01):27.

8. Shobeiri F, Hesami E, Khodakarami B, Soltanian A, Effect of Counseling on Preventive Behaviors of Osteoporosis in Women Referred to Health Centers in Hamedan, Iran in 2015. J Educ Community Health. 2015 Dec 15;2(3):51-7

9. Sedlak C.A, Doheny M.O, Jones S.L, Osteoporosis 
education programs: changing knowledge and behaviors. Public health nursing. 2000 Sep 1;17 (5):398-402.

10. Khorsandi M, Shamsi M, Jahani F, The Survey of Practice About Prevention of Osteoporosis Based on Health Belief Model in Pregnant Women in Arak City. JRUMS. 2013; 12 (1) :35-46.

11. Ebadi FardAzar F, Solhi M, Zohoor A, Ali H.M, The effect of Health Belief Model on promoting preventive behaviors of osteoporosis among rural women of Malayer. J Qazvin Univ Med Sci. 2012; 16 (2) :58-64.

12. Khani jihoni A, Haidarnia A, Kave M, Hajizadeh E, Askari A, Naghizadeh M, Designing the validity and reliability of osteoporosis prevention instrument based on health belief model in women. Journal of Ilam University of Medical Sciences. 2014;22 (3):127-36.

13. Shohaezadeh D, Application of hoath Belief Model in Prevention of osteoporosis in Volunteers of khorramabad city health centers, Iran. MSc nursing thesis; Tehran University of Medical Sciences; Tehran; 2012. 58p.

14. Mirzaei E, Health education and health promotion in text book of public health.Tehran: Rakhshan Inc;2004. 96p.

15. Hazavehei S.M, Taghdisi M.H, Saidi M, Application of the Health Belief Model for osteoporosis prevention among middle school girl students, Garmsar, Iran. Education for health. 2007 May 1;20 (1):23 .

16. Ghaffari M, tavassoli E, Esmaillzadeh A, Hassanzadeh A, Effect of Health Belief Model Baseel intervention on Promoting nutritional behaviors about osteoporosis Prevention among students of fernale middle schools in Isfahan, Iran. J Edu Health 2012; 1(2): 14.

17. Jalilian F, Emadi S.H, Mirzaie M, Barati M, The survey physical activity status of employed woen in Hamadan University of medical sciences. Toloo-eBehdasht. 2011;9(4): 89-98.

18. Gorgi Z, Assadollahi Z, Ghaffarian A, Rezaeian M, The Prevalence of Musculoskeletal Disorders in the Employees of Office Systems at Rafsanjan University of Medical Sciences in 2012. JRUMS. 2014; 12 (12): :991-1002

19. Safar M, Shajayzadeh D, Ghofranpourf, Heydarniu A, Hajiagha A, Theories models of health Promotion and health education methods work. Thehran: Sobhan Inc; 2010.p20.

20. Jadid Milani M, Arshadi F, Asadi Noqabi A, Community Health Nursing 1 \& 2 \& 3. Third Edition,Tehran: Andisheh Rafi Inc; 2007. 151p.

21. Ildarabadi A, Tabaraghi F, Public Health Nursing Consulates 1, 2, and 3. Third Edition, Tehran; Sovet Negar Publishing; 2007. 91p.

22. Black J, Hawk J.H, Keene A.M, Medical surgical of nursing. Philadelphia; Saunders Inc; 2003.5223 P.
23. Farmanbar R, Study on Health Maintenance Method in Students of Guilan University of Medical Sciences. Guilan University of Medical Sciences Journal.2003;12(46):34-43.

24. Cooper C, Epidemiology of Osteoporosis. Osteoporosis Interational. 1999; 9(2):S2-8.

25. Kneal J, Davis P, Orthopedic and trauma nursing. $2^{\text {nd }}$ Ed. Philadelphia; Churchil Livingstone; 2005p $380 \mathrm{p}$.

26. The International Osteoporosis Foundation (IOF). Facts and statistics about osteoporosis and its impact; 2008. Available from: http: www. iofbonehealth. org /facts- and statistics. html \# factsheet- category- 25

27. Zhu K, Greenfield H, Du X.Q, Zhang Q, Ma G.S, Hu X.Q, Cowell C.T, Fraser D.R, Effects of Two Years. Asia Pacific journal of clinical nutrition. 2008 Jan 1;17(S1):147-50.

28. Ailinger R.L, Braun M.A, Lasus H, Whitt K, Factors influencing osteoporosis knowledge: a community study. Journal of community health nursing. 2005 Sep 1;22(3):135-42.

29. Chan K, Anderson M, Exercise interventions: defusing the world's osteoporosis time bomb. Bulletin of the World Health Organization. 2003; 81: 827- 830 .

30. Strange F, Osteoporosis (Proceedings of the Rheumatology Research Center of Tehran University of Medical Sciences and Health Services), Andishamd Publications; 2002. 441432p.

31. Katz S, Osteoporosis in patients with inflammatory bowel disease: Prevention and treatment. Rev Gastroenterol Disord. 2006 Spring;6(2):63-71.

32. Cuddihy M.T, Gabriel S.E, Crowson C.S,Atkinson E.J,Tabini C, Fallon M.W, Melton L.J, Osteoporosis intervention following distal forearm fractures. Arehintem Med. 2002; 162: 421- 426.

33. KalkWalf H.J, Khoyry J.C, Lanphear B.P, Milk intake during childhood and adolescence, adult bone density and oateoporosis fractures in US women. Am J ClinNutr. 2003; 77 (1): 257- 265.

34. Nguyen T.V, Kelly P.J, Sambrook P.N, Gilbert C, Pocock N.A, Eisman J.A, Lifestyle factors and bone densirty in the elderly: Implications for osteoporosis prevention. Journal of bone and minera research. 2009; 9(9); 1339- 1346.

35. Chan K, Anderson M, Exercise interventions: defusing the world's osteoprosis time bomb. Bulletin of the World Health Organization .2003; 81: 827830.

36. Abd El Hameed A, Emam H, Fouad W, Abd E Mohsen A, Evaluation of health education intervention program for female employees toward osteoporosis. Journal of Applied Science Research. 2008; 4(7): 863-870.

37. Tussing L, chapman- novakofski K, Osteoporosis prevention Education: behavior theories and calcium 
intake. J Am Diet Assoc.2005; 105: 92- 97.

38. Prentice A, Diet, Nutrition and the Prevention of osteoporosis. Public Health Nutrition. 2004; (7): 227 $-243$.

39. Benjamin I.J, Griggs R.C, Wing E.J, Gregory Fitz J, Andreoli and Carpenter's Cecil Essentials of Medicine, 9th Edition, Philadelphia, PA; Elsevier/ Saunders; 2016.

40. Kasper M.J, Peterson M.G, Allegrante J.P, The need for comprehensive educational osteoporosis prevention programs for young women: Results from a second osteoporosis prevention survey. Arthritis Rheum. 2001 Feb;45(1):28-34.

41. Naunton M, Peterson G.M, Jones G, Griffin G, Bleasel M.D, Multifaceted educational program increase prescribing of preventive medication corticosteroid induced osteoporosis. Journal of Rheumatology. 2008; 31 (3): 550.

42. Morowatisharifabad M, Ghofranipour F, Hidarnia A, Ruchi G, Ehrampoush M, (2006). Self-efficacy and health promotion behaviors of older adults in Iran. Social Behavior and Personality: An international journal, 34, 759-768.

43. Centers for disease control and prevention. Physical activity [Accessed May 12, 2010]. Available from: http:// www. cdc. gov/ physicalactivity/ index. Html

44. Strong W, Malina R, Nlimkie C, Daniels R, Gutin $\mathrm{B}$, To reviw the effects of physical activity on health and behavior outcomes and develop evidence- based recommendations for physical activity in youth. The Journal of pediatrics 2005 Jun; 146 (6): $732-737$.

45. Sisson S.B, Katzmarzyk P.Y, International prevalence of physical activity in youth and adults. Obesity review. 2008 Jul; 9(6): 606-614.

46. Zia'I V, Kelishadi V, Ardalan G, gheyratmand R, Majd Zadeh S, Motaghian M, Physical Activity of Iranian Students, Caspian Studies, Iranian Children's Diseases Journal, Summer 2005;16(2):164-157.

47. Heidari Nia A, Discussions in the health education process. Tehran, Naser Publication; 2003. 109p.

48. Heffeman M.P, Saag K.G, Robinson J.K, Callen JP, Prevention of osteoporosis associated with chronic glucocorticoid therapy. JAMA. 2006; 295 (11): 1300- 1303.

49. Jalili Z, Nakhee N, Askari R, Sharifi V, Knowledge, Attitude and preventive practice of women concerning osteoporosis. Iranian Journal of public health .2007; 36(2): 19-25.

50. Eslamian L, Jamshidi A, Knowledge, attitude and behavior regarding osteoporosis among women in three age groups: Shariati hospital, Tehran. Tehran University Medical Journal. 2008; 65(14):16-21.
51. Torshizi L, Anoosheh M, Ghofranipour F, Ahmadi F, Houshyar-rad A, The Effect of Education Based on hearth Belief Model on Preventive factors of osteoporosis among postmenopausal women. Iran Journal of Nursing. 2009; 22(59): 71-82.

52. Shojaezadeh D, Salehi L, To Evaluate of Efficacy of Education based on heaith Belief model on knowledge, Attitude and Practice amangwemen with Low socioeconomic Status Regarding osteoporosis Prevention. Iranian Journal of Epidmiology. 2011; 4(2):30-37.

53. Huang C.H, Su C.H, Chien L, Guo J, The effectiveness of an osteoporosis rrevention program among women in Taiwan.sciverse sciencedirect.2011.24:29-37

54. Malak M,Toama Z, The effect of osteoporosis health education program based on health model on knoledge and health belife toward osteoporosis amoung jordanian femail Teachers. European Scientific Journal.2015.1857-1881.

55. Al Seraty W.H.H, Ali W.G, The Impacts of Health Belief Model Based Intervention for Osteoporosis Prevention among Female Students in Al Dawadmi Applied Medical Science, ShaqraaUniversity, Saudi Arabia. Journal of Biology, Agriculture and Healthcare 2014; 4(7):125-31.

56. Baheiraei A, Ritchie J.E, Eisman J.A, Nguyen T.V, Psychometric Properties of the Persian version of the osteoporosis knowledge and health belief questionnares. Maturitas. 2005 Feb 14;50(2):134-9.

57. Torshizi L, Anoosheh M, Ghofranipour F,Ahmadi F, The Effectof Education Based on HealthBelief Model on Preventive Factors of Osteoporosisamong Postmenopausal Women.Iran J Nursing 2009;59 (22):71-82.

58. BaghianiMoghadam M, Khabiri F, Morovati Sharifabad M, Dehghan A, Falahzadeh H, Determination of social variables affected the health belief model in adopting preventive behaviors of osteoporosis. TB. 2016; 15 (2) :45-57

59. Vahedian-Shahroodi M, Esmaily $H$, Tehrani $H$, Amini A, Mohaddes-Hakkak H, Lael-Monfared E, The Impact of Health Education based on the Health Belief Model on Improving Osteoporosis preventive Behavior among Women . Health Develop J. 2016; 5 (3) :226-237

60. Khorsandi M, Shamsi M, Jahani F, The Survey of Practice About Prevention of Osteoporosis Based on Health Belief Model in Pregnant Women in Arak City. JRUMS. 2013; 12 (1) :35-46. 